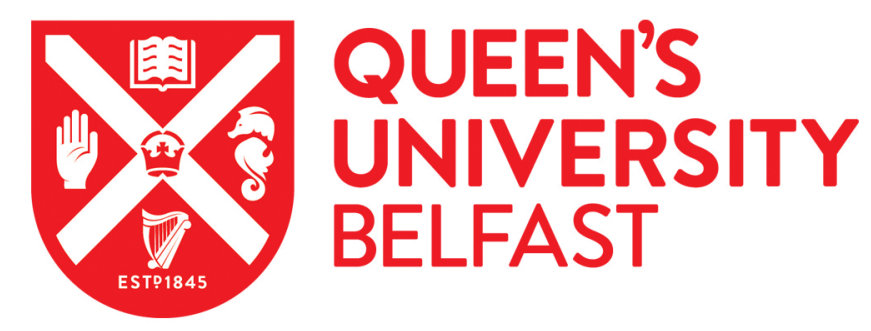

\title{
Sabotage and Science: Navigating Between the Disciplines
}

\author{
McAreavey, R. (2007). Sabotage and Science: Navigating Between the Disciplines. International Journal of \\ Interdisciplinary Social Sciences, 1 (5), 1-10. \\ http://www.scopus.com/inward/record.url?scp=80051516329\&partnerlD=8YFLogxK
}

\section{Published in:}

International Journal of Interdisciplinary Social Sciences

\section{Document Version:}

Peer reviewed version

Queen's University Belfast - Research Portal:

Link to publication record in Queen's University Belfast Research Portal

Publisher rights

〔 2007 The International Journal of Interdisciplinary Social Sciences. Please ask from the publisher permission before reproducing this article.

\section{General rights}

Copyright for the publications made accessible via the Queen's University Belfast Research Portal is retained by the author(s) and / or other copyright owners and it is a condition of accessing these publications that users recognise and abide by the legal requirements associated with these rights.

Take down policy

The Research Portal is Queen's institutional repository that provides access to Queen's research output. Every effort has been made to ensure that content in the Research Portal does not infringe any person's rights, or applicable UK laws. If you discover content in the Research Portal that you believe breaches copyright or violates any law, please contact openaccess@qub.ac.uk. 


\section{Introduction}

Interdisciplinary research is enjoying a new found popularity, with a swathe of research funding available at a national and European level. For instance funding opportunities for interdisciplinary research are offered via programmes within the RCUK (Research Councils, United Kingdom); the European Commission's Framework Programme and the European Science Foundation initiatives. Much of the increased pressure to conduct interdisciplinary research stems from an evolving relationship between science and society whereby citizens are able to exert greater direct and indirect influence over research agendas. Predominant influences come from society and are filtered through the policy and funding framework.

Twenty-first century society is managed through a complex interaction between structures of government and the governed, resulting in a powerful consumer base that demands greater accountability and so requires research that is relevant and responsive to society (Nowotny, et al., 2001; Nowotny, 2003 and Klein, 2004). The challenge of the environment in general and sustainable development in particular provides an excellent example of the interplay between science and society and of the need to address complex issues beyond a single discipline (Klein, 1990). Notwithstanding the general societal interest in sustainable development (HM Treasury, 2006), this emerging relationship between research and society is aptly demonstrated by the RCUK Rural Economy and Land Use (RELU) Programme. It represents a change in the way that the UK government thought about and dealt with rural issues, including a shift from a production-driven logic to one oriented to the consumer and a movement from primary production to sustainable development (Lowe and Phillipson, 2006). The needs of the consumer become paramount in this new approach. Furthermore this new type of funding structure with its focus on the complex issue of sustainable development ensures that it is addressed 'holistically', that is economic, social, environmental and technological issues are considered. As a result meaningful research on the subject of sustainable development must be conducted across disciplinary boundaries. The funding streams not only provide strong incentives, but require researchers to cross disciplinary boundaries and develop integrative approaches, thereby engaging in interdisciplinary research.

Much of the driving force for interdisciplinary research tends to be exogenous to the academe. Intellectually the literature would suggest that the drive for interdisciplinary research does not appear to be as strong and yet this is where the interdisciplinary research actually takes place. Sokal claims that the two cultures [sciences and humanities] are probably further apart in mentality than at any time in the past 50 years (1996b:2). The type of knowledge that is generated within a discipline is not always fully understood or respected and so interdisciplinary work can represent a mere 'juxtapositioning or subordination of the concerns of one subject matter over another' (Collini, 1993:53). Consequently interdisciplinarity suffers from unease around the quality of the research output (Gibbons et al, 1994; Klein, 1996 and Mansilla and Gardner, 2003). Not only is there a failure to truly integrate the research problem, but lack of equality can ensue, with one discipline assuming a superior and powerful position over the other. This cultural and intellectual divide possibly poses the greatest threat of all, with most researchers who cross the disciplinary divide failing to recognise the barriers that exist as a result of their disciplinary position (Pélé and Norgaard, 2005), a huge gulf that was identified by Snow back in the mid-twentieth century (Snow,1993 [1959]). While the institutional framework may reward interdisciplinary working through short term funding schemes, it does not necessarily have room to fully acknowledge or incentivise intellectual collaborations across the disciplinary divide. For instance in the UK the Research Assessment Exercise (RAE) does not have a system for distinguishing between publications from a single discipline and those that are published from interdisciplinary research (http://www.rae.ac.uk/). As a result, for example single authored articles in the social sciences will always have a greater value than multiple authored articles. The latter being an expected outcome from genuinely interdisciplinary collaboration and also a publication standard within the natural and physical sciences. 
In an attempt to unpack these issues that arise as a result of crossing traditional disciplinary boundaries, this paper examines the institutional and intellectual challenges that accompany working in an interdisciplinary academic environment. While on the one hand there appears to be an institutional drive to develop structures to support interdisciplinary research (Nowotny, et al., 2001), there is also a danger that the cultural divides are so established that social forces operate to make this divide ever more rigid (Snow, 1993 [1959]), this being a necessary evil of disciplinarity (Fuller, 2003). In other words this article is concerned with the apparent disharmony between the forces and influences of disciplinarity and the aspiration of conducting interdisciplinary research. The research is carried out from the perspective of a social scientist working in an academic unit primarily made up of natural scientists. In so doing it seeks to contribute to the knowledge relating to the process of interdisciplinary research (Moxey and White, 1998; Klein, 1990). The article begins by examining the history and theory underpinning both the natural and social sciences, highlighting the role of the crisis within the social sciences. It then considers the notion of interdisciplinarity before introducing the research. Issues that arose within the research are analysed including power, knowledge, the human factor and the potency of the disciplinary base. Key matters impacting on the future interdisciplinary research are then presented within the conclusions.

Social sciences in the shadow of traditional science?

Traditional science (natural and physical) had a huge amount of leeway to practice under its own regulation up to the mid-twentieth century, working according to the 'scientific method' using peer review to act as a systematic check (Yearley, 2005). Scientists were infrequently called to account for what they did and so had a huge incentive to draw and police their own boundaries. There was a perception that the scientist was driven by intellectual curiosity and did not act with a vested interest. Knowledge reflected how the world was; the researcher was merely a cipher (Yearley, 2005). Although this privileged position became weakened as science became funded from the mid 1800 s onwards, it provides a strong cultural identity for the natural and physical sciences.

In contrast the development of the social sciences was less autonomous. Saint-Simon (1760-1825) was interested in the development of a science of society and he argued that for it to be viable and constructive, it must be underpinned by the same rigorous principles as found in the natural sciences His ideas were developed by Comte $(1798-1857)$ who promoted the application of positivism to the science of society, or sociology, and its concern with pure objective fact. In this way sociology has its origins in the desire to replicate the approaches of the natural sciences by producing cumulative and predictive theories, demonstrating the ascendancy of the natural sciences. But as Flyvberg (2001) points out, analysis of the social sciences involves issues of values and power. He draws attention to Aristotle's concept of phronesis (that is wisdom or practical reason) showing how it has an important function within the social sciences, but crucially it cannot easily be summarised by universal rules. By exercising phronesis or judgement and consideration, the successful social scientist grasps the importance of culture, values and power in society and so understands how to behave in particular circumstances, navigating a course of action that relies on interaction between the abstract and the concrete.

\section{Disciplinary paradigms and the crisis of the social sciences}

That the social sciences cannot be encapsulated by universal rules in the same way as natural science has led to the radical position of the post-modernists where exponents claim that there is no universal truth, everything is relative. This has caused many problems for sociology in particular and for the social sciences in general. Specifically it stems from different disciplinary frameworks or 'paradigms'. Kuhn (1962) famously used the term 'paradigm', borrowing it from linguistics, to describe the framework within which scientists operate and thereby securing the wider usage that the concept still enjoys today. Researchers within a particular discipline operate within a paradigm of symbolic generalisations, models and exemplars, all of which represent the problems (and subsequently) solutions of that discipline as defined through social 
constructions (Kuhn, 1962). Foucault describes disciplinarity as comprising 'set[s] of rules...the system of the referentials.' Foucault, (2003[1972]).

As a result each discipline has its own ontology; that is a common understanding of the relations between the kinds of factors that make up the disciplinary domain - norms, practices, structures, persons, institutions, roles. However, the scientific paradigm has more in common than that of other disciplines -social sciences and humanities. Scientific culture has common attitudes, common standards and patterns of behaviour, common approaches and assumptions, even though disciplines within may not completely understand each other (Snow, 1993:9 [1959]). This results from a shared epistemology; that is a common belief about the nature of knowledge. For example, the law of thermodynamics or the theory of relativity is common within scientific disciplines. In this way beliefs are given and shared across the scientific disciplines. Meanwhile in the social sciences different epistemologies exist within and across the disciplines such as post-modernism, realism, empiricism and positivism. There is no consensus on the nature of knowledge; even this must be justified as it is not given.

A consequence of the lack of common standards and approaches within social science is the perception that it does not produce rigorous, objective knowledge. Compounded with the crisis caused by post-modernism, it is often viewed as a discipline in disarray. Perhaps the so-called 'Sokal affair' provides the best illustration of the difficulty that these matters cause for the social sciences. The prestigious cultural studies journal, Social Text published an article by Alan Sokal aiming to contribute to a dialogue between humanists and natural scientists and in so doing sparking the 'Science Wars' (Sokal, 1996a). In this article Sokal claims that he is 'a stodgy old scientist' whose job it is to discover 'objective truths about the world'. In fact this is also the job of the social scientist (Shortall and McAreavey, 2006). Sokal's piece considers how in certain intellectual circles "all facts are "socially constructed", scientific theories are mere "myths" or "narrations"' (Sokal and Bricmont, 1999:2). By focusing in this way on the crisis of post-modernism, Sokal missed an opportunity to unpick the social influences on science in general through traditions such as publications and funding. For example in the case of medical sciences the way in which 'successful' drug trials tend to be published or the role of the pharmaceutical industry in funding particular research and developing new technologies.

\section{Interdisciplinarity}

Interdisciplinarity is a complex term and its meaning is not always shared. Its classification and characterisation is varied within the literature, there is an impressive array of prefixes used to describe working across the disciplinary divide such as trans-, intra-, cross-, multi- and pluri(see for example Kockelmans, 1979 and Klein, 1990) evidencing a lack of standard nomenclature (Aram, 2004). Despite this there appears to be consensus that interdisciplinarity is about increased levels of knowledge integration ${ }^{1}$. Moreover interdisciplinarity is used to address issues that are too complex to be dealt with sufficiently through a single discipline (Klein and Newell, 1998). It creates knowledge that has social utility (Filemyr, 1999; Klein, 1996) and 'integrates knowledge and modes of understanding in ways that would have not been possible through single disciplinary means' (Mansilla and Gardner, 2003). Mansilla and Gardner are concerned that disciplines themselves are integrated, rather than integrating multiple perspectives and so the aim is to understand or solve a problem rather than simply to juxtapose a number of disciplines. The cultural differences of the disciplines is highlighted in a seminal OECD report that describes an interdisciplinary group as consisting of 'persons trained in different fields of knowledge (disciplines) with different concepts, methods, and data and

\footnotetext{
${ }^{1}$ Interdisciplinary research that has social utility and integrates researchers with non-academic participants to address real world problems has been labelled transdisciplinarity (Klein et al., 2001, Tress et al, 2005) Meanwhile Sperber (2003) discusses research that falls across several disciplines as being interdisciplinary in nature.
} 
terms organised in a common effort on a common problem with continuous intercommunication among the participants from the different disciplines' (OECD,

1972:25-26).

According to the literature interdisciplinarity therefore poses huge challenges, least of all in that it relies on academics coming together in a manner that transcends, but also erodes, disciplinary boundaries. The benefits are unclear and the risks are great (Fuller, 2003). However, as this discussion has shown the power of funding and the influence of a consumer oriented society is compelling, these factors can create an environment in which it is attractive to conduct interdisciplinary research. This typically occurs within the academe, and it is this environment that forms the focus for the remainder of this article as it seeks to contribute to our understanding of working across the disciplinary divide by unpicking the tension between a disciplinary and an interdisciplinary approach to research.

\section{An interdisciplinary setting: the Gibson Institute}

It was after the reorganisation of the University in September 2005 that I came to find myself within a Faculty of Medical and Life Sciences in a School of Biology. True I was still in the Gibson Institute for Land, Food and Environment, but this position represented a move from being a free floating structure within the Faculty of Agriculture to being firmly embedded within the Medical Faculty under the jurisdiction of the School of Biology. Like many others across the University I found myself in an academic environment that was not only a surprise, but was a challenge. There were boundaries to establish as I discovered the different personalities that lay behind the new faces. However being a sociologist at heart, most of all I was fascinated by what social fallout this new world order would bring. I decided to examine the relationships between the natural and social scientists in this new structure. Hence this research was conducted using covert participant observation whilst working in the Gibson Institute for Land, Food and Environment (GI) within the School of Biology (SOBB). All names have been changed to preserve anonymity. At the time of the research the Institute was physically housed in a small detached building located approximately twenty minutes by foot from the SOBB office, from which it also received remote clerical support.

The interaction that is cited here is sourced mainly from School Board meetings and from planning meetings for a research project on sustainable catchment management. School Board meetings were held on a weekly basis and formed the main channel of communication between the Head of School (HoS) and the Academic staff. The sustainable catchment management project was an interdisciplinary research programme led by the Director of the Gibson Institute in conjunction with a range of researchers from across the University, including natural scientists. Funding was sought from the RELU programme and meetings were held according to the requirements and the timetable of the funding body.

The mission of the $\mathrm{Gl}$ is to ensure the sustainability of the farming sector in Northern Ireland and in particular it is concerned with the plight of the small farmer. The Institute engages with a broader programme of activity including sustainable development and rural development. The staff is comprised of social scientists, specifically two sociologists, an anthropologist and a political scientist. Only one member of staff had been in the Institute for more than one year before the research commenced. It delivers three MSc programmes in the subjects of rural development and sustainable development. In addition staff and research students are engaged in a varied programme of research that broadly fall within the themes of sustainable development and rural development including community involvement and participation, sustainable catchment management, social exclusion in rural areas and the position of women in farms and rural development. The social science base of the staff is reflected in this research agenda.

While conducting the research a number of emerging themes were noted; this article focuses on three, all of which are discussed in the following section. Firstly power was important in 
terms of institutional structures, the accompanying bureaucratic hierarchy and status. Knowledge and perception of knowledge of other disciplines played an important function in the interplay between the disciplines. Finally, disciplinary domains with their respective cultural norms, represented often insurmountable challenges to conducting effective interdisciplinary research within the School.

Power and hierarchies: consensus and conflict

School Board meetings are typically the forum in which issues affecting School members are raised. Within the social sciences it is seen as a two-way communication channel, staff members share information with colleagues and their Head of School (HoS) and in turn the HoS is able to disseminate information to her staff. It has a social function of bringing everyone together and is often conducted informally, frequently contentious issues are discussed and meetings involve heated debate (Director, GI; June, 2006). School meetings within SOBB were evidently held on a more formal basis where consensus rather than conflict was the norm. The structural hierarchy was always present both physically and metaphorically. Physically the HoS sat at one end of a polished wooden table, while academic staff members were seated around the opposite end of the table. The alternate venue was a lecture theatre and the HoS sat at the top of the room while staff sat in rows facing him. All interaction was conducted in a formal manner through the Chair (the HoS). The School Manager attended these meetings but rarely made a contribution nor was she encouraged to participate except to clarify a point of information. Discussions reinforced hierarchical structures with constant referral by the HoS to the Senior Management Team as 'the Front', even though he was part of this structure. As the following quote reveals, he gave a continual message that the School was not part of the central University. Indeed the language used to describe this part of the hierarchy suggests a conflict of interest but also an attitude of rebellion with a complete failure to take responsibility for his management position and function within the University overall.

'Well Bob, or whoever in the Front can tell us to do what the University wants, but we have our own teaching and research to do and I suggest we get on with it despite these schemes coming from the Front'. (HoS; November, 2005)

In a less obvious and immediate sense the HoS retained a powerful position. Notice of School Board meetings was often given at the last minute, for instance notice was given on 9th February at $5.32 \mathrm{pm}$ for a $2 \mathrm{pm}$ meeting on the following day, the pre-determined agenda and attached papers circulated to academic staff. This short timeframe reduced the amount of time staff would have to review the distributed papers; there was little room for comment from School staff. At this particular meeting in February, the content of the Academic Plan was to be discussed, but staff had only been sent a copy the previous evening. It transpired that the Gl contribution to the School's Academic Plan had been substantially rewritten to the extent that it was no longer recognizable as the document submitted by Gl staff. Major changes included the omission of large research initiatives and the removal of key staff. The HoS assumed a role of complete power by failing to consult on the changes made and overtly exercising his authority in the process of Academic Planning.

The strength of the HoSs position was in no doubt. Not only was he influencing what issues were discussed revealing the second dimension of power (Bachrach and Baratz, 1962), but by dictating and operating through an unrealistic timetable he was influencing individuals' ability to shape the very way in which they participated in the meeting. Furthermore he was able to carry out his will against resistance from staff within the School, such was the format of the School Board that it would not have been appropriate to discuss the amendments to the $\mathrm{Gl}$ Academic Plan. The HoS exercised a hidden dimension of power (Lukes, 1974).

Perhaps this type of approach is to be expected in a School of predominantly natural scientists. As natural scientists approach their research from a common epistemological basis, they are not prepared for the 'competition and even open hostility among social scientists from 
different fields' (Léle and Norgaard, 2005:970), let alone that which arises within the same field. Sociologists, and indeed social scientists, are well known for their different viewpoints; engaging in lively debates is an important part of their sense of existence. Given these contrasting cultures and values it is hardly surprising that the norm within SOBB is one of apparent consensus with minimal debate. This meant that SOBB staff members were less likely to question the powerful Head of School in such a public space, these individuals may have perceived that questioning his motivation and action would be looked upon unfavourably and would also would indicate a lack of knowledge on their behalf. School meetings were therefore a mechanism for the HoS to communicate information and, in a superficial way, to elicit the views of his staff. All of this was conducted in a controlled environment, the language and the actions of the Head of School were carefully planned and a veneer of consensus and mutual understanding prevailed, it was the norm.

\section{Knowledge and superior knowledge}

Lack of knowledge was something that was not readily addressed within the School. While this phenomenon is not exclusive to a school of natural sciences, the matter of concern to this discussion relates to knowledge of the social sciences. The HoS was unable to review research proposals from the Gl with their focus on social science as he claimed to have insufficient knowledge of the discipline (HoS, November, 2005). Similarly, one of the Gl staff wished to have her status transferred from academic related to academic. Within the University this process involves an internal application to the appropriate committee, requiring full endorsement of the relevant HoS. When the time came for the paperwork to be completed the HoS claimed he did not have 'sufficient knowledge of the social sciences' to make a judgment on the research outputs detailed in her application (HoS, December, 2005). On the basis of this incomplete knowledge he nevertheless proceeded to make recommendations to the committee, failing to endorse the application. This was contrary to the position of the $\mathrm{Gl}$ Director who was confident that the academic outputs were sufficient to meet the requirements of the Committee. Instead the HoS suggested via the GI Director that this particular individual was not ready for an academic post, and ought to consider a Research Assistant post for twelve months (GI, January, 2006). This have virtually halved that individual's salary, while also substantially altering her status in the University.

Not only was the lack of knowledge of the social sciences problematic. The perception of the quality of knowledge across the disciplines posed a difficulty. Many natural scientists believe that science is value neutral and superior to social sciences. The differing quality of knowledge of the two disciplines was often referred to by the natural scientists in SOBB, sometimes subtly, but often more explicitly. In a manner reflecting that of the postmodern generator (http://www.elsewhere.org/pomo), the following comment was made in a meeting:

'If the university is willing to put money into some social paradigm of learning methods (guffaw) then they can fund this.' (School Board, December, 2005)

The Natural Scientist in question was making reference to the fact that the University had made monies available for a virtual Centre for Sustainability. Meanwhile they had unsuccessfully applied for University funds to undertake sustainable development research with a natural science slant. Some debate followed about applying to the University for funding for projects within the School. Even though the matter under discussion was the capacity to access research funding from the University this quickly became sidetracked to a debate on the superiority of natural science knowledge over social science. By extension if the social scientists could get some funding, then the natural scientists believed that they should not have a problem accessing monies from the University.

'What has the Centre for Sustainability done? At least if the University had given us [Natural Scientists] funding we could have shown the results of our work.' (School Board, December, 2005) 
There was a lack of respect towards knowledge in general and more precisely the social sciences. This is not surprising given the hierarchies that exist between different types of knowledge within the University structure (Lau and Pasquini, 2004) and beyond to international structures. For instance the Intergovernmental Panel on Climate Change was initiated by natural scientists, even though the matter of climate change cuts across society (Lélé and Norgraad, 2005). Such a divide between the two cultures is deeply rooted (Snow, 1993 [1959]). It conforms with the general stereotypical belief that social systems are simplistic and that social science is inferior to the natural sciences. Consequently natural and physical scientists are perceived as being 'by and large the soundest group of intellectuals we have' (Snow, (1993:13 [1959]).

\section{The human factor and disciplinary domains}

The reality is that scientific research is a human activity. And so '[S]cientists can also be selfish, arrogant and prejudiced. In case these descriptions do not apply to you, just think about your colleagues!' (Bricmont, 1997). Bricmont argues the case for 'careful and reasoned' historical, sociological and philosophical analyses (ibid). The human side of scientific research was all too apparent at a research project meeting convened and led by staff in the $\mathrm{Gl}$ as part of the ongoing development of an interdisciplinary research bid to the RELU programme. As the proposal was being developed gaps in expertise were identified. One area in which the team needed expertise was on the topic of water biology, specific peer review comments indicates that the natural science element of the bid was a serious weakness and that the proposed research team did not have the expertise:

'This whole package seems very much of an outlier. It is dealing with one specific issue, which might well be very interesting, but there is no case made that this small bit of the ecological story on rural sewage and insects is a major issue for SCM. The package is poorly integrated with the others, and it is hard to see how it is going to inform the development of "integrated mechanisms" (RELU Anon Reviews, Ref 19C).

'The proposal appears to be synonymyzing package D with catchment biodiversity. They are not the same thing. What I cannot see is how this detailed ecological study of the effect of sewage nutrient input on riparian foodwebs can be upscaled to more synoptic issues surrounding sustainable catchment biodiversity' (RELU Anon Reviews, Ref 19A).

At a meeting convened in the $\mathrm{Gl}$ to discuss these comments the natural scientists arrived with their HoS. A brief exchange between the individuals in the project management team and the main natural scientist, Peter revealed that he believed the management team did not have the knowledge to make a judgement on the quality of the natural science, even though the project management team was quoting from the peer reviewed comments. Peter disputed the points raised telling the project management team members that they did not understand the science, he disagreed with the other scientists on the team who confirmed the management team's knowledge and had these points reinforced by his HoS (Director, Gl; June 2005). Furthermore Peter articulated his argument forcefully by raising his voice and pointing his finger. The institutional hierarchies were so strong that they were used as a means of posturing; that is as a defence of academic territories against perceived disciplinary dilution and corruption associated with interdisciplinary work (Klein, 1990). The inability of the natural and social scientists to engage in a meaningful discussion in response to the anonymous reviews, reveals the need for 'intellectual bilingualism' (after Snow, 1993 [1959]), but also the need for openness towards this concept. That is, an acceptance of the possibility of disciplines engaging in meaningful debate outside of their bailiwick. 
It further demonstrates the failure of this project to develop the research challenge in a truly integrative way that transcended disciplinary boundaries. When matters became difficult, researchers reverted back to the comfort of their discipline. Moreover, even if the challenge of integrating the disciplines had been achieved, another difficulty lay in identifying a shared framework. Due to the lack of a shared paradigm for interdisciplinary research there is no way of judging whether a piece of interdisciplinary research is rigorous in the same way as it is possible to measure the quality of disciplinary research output.

The peer review comments on the final proposal suggest that had the appropriate biological scientist been involved, the project would have been in a stronger position to win RELU funding.

'The natural science elements of the programme sit awkwardly with the social science ones. The complete absence of any hydrological input and context is a major omission'. (RELU Assessor comments for RES-227-25-0019, July 2005).

On a stronger note '...the panel ... was disappointed that the natural science element had not been significantly improved since the outline stage' (RELU, July 2005).

Lack of honesty and the failure to admit insufficient knowledge meant that while in the short term the expertise and knowledge of the biological scientists remained under no doubt, in the medium term their credentials were open to suspicion from the social scientists and in the longer term the research did not receive scarce and highly prized research council funding. The research process is evidently subject to the weaknesses of human nature. Individuals, as Bricmont (1997) argues, can be philosophically confused, but they can also exaggerate the relevance and level of confirmation of their theories thus falling prey to that common human attribute of an inflated ego.

\section{Conclusions}

That research institutions have responded to the demand for 'socially-robust and epistemologically eclectic' research (Nowotny, et al., 2001:198) by establishing interdisciplinary units, research centres and research clusters was evident within this research. The GI, although a predominantly social science based research institute, was housed within a school of natural sciences. Aram (2004) notes how such institutional changes in recent decades have reduced the influence of traditional organisational structures, increasing not only the autonomy of individual researchers but also the diversity of intellectual objectives and theoretical approaches. However the autonomy of individual researchers in promoting interdisciplinarity per se appeared to be superseded by the potency of traditional institutional structures. Disciplinary affiliations were shown to provide comfort zones for academics operating in what is an increasingly cut-throat and uncertain environment. Indeed it has been noted that academic life tends to exaggerate the power and importance of disciplinary affiliations to the neglect of other allegiances (Collini, 1993). This was evidenced in the development of the interdisciplinary research project where disciplinary loyalty took precedence over interdisciplinary objectives.

This research further revealed how intellectual, cultural and institutional practices all contributed to the identity of the school of natural sciences. The strength of the disciplinary base can therefore not be underestimated, nor should it be overlooked as a basis for conducting interdisciplinary research. Researchers are familiar with the particular culture and norms that pervade their own discipline, they have the capacity to use their own specialist disciplinary language and they recognise rigorous science through the application of accepted quality standards. A distinguishing feature of the social and natural sciences was the existence of sociological factors including socialisation, organisation and rewards (Becher, 1989). The process by which the Gl staff member attempted to achieve academic status was far from 
opaque. While the experience of the GI Director was that progression to academic status required fulfilling certain criteria, the practice of the HoS revealed a muddied process, with an unclear system of reward. Social scientists were disadvantaged in career development due to the lack of knowledge of their discipline in the school in which they were situated. Meanwhile the act of questioning the rigour of aspects of the Natural Science within the research bid was met with open hostility and was evidently deemed by the Natural Scientists as inappropriate practice. Such was the strength of the disciplinary base that it caused a barrier to conducting truly interdisciplinary work (Pélé and Norgaard, 2005) and also to facilitating interaction with disciplines that were new to the school.

A fundamental lack of understanding of the process of working in an interdisciplinary way led to the failure of a research project to attract funding. By engaging in academic posturing and advocating hierarchies of knowledge, the natural scientists not only questioned the legitimacy of the other members of the research team to judge the quality of their science via peer review comments, but they also failed to transform the intellectual orientation. They did not contribute to significant discussions of the research topic that would, at one level develop meaningful and trusting working relations, while at another would encourage debate to facilitate the integration of knowledge and the realignment of disciplinary boundaries (Fuller, 2003). As a result the research was possibly better described as juxtapositioning of disciplines than as truly interdisciplinary research (Collini, 1993), a view ultimately shared by the RELU panel:

'... the panel agreed that this project was more like a cluster of monodisciplinary projects...' (July 2005, RELU, email correspondence).

On the one hand, academic institutions tend to reinforce these powerful disciplinary affiliations, while on the other hand society and also in a somewhat contradictory manner, the academe, through research funding schemes, provide incentives to cross disciplinary boundaries. To do this effectively researchers need a wider vocabulary that allows them to engage in meaningful debate across the disciplines. Typically, social scientists do not have the confidence or language that allows them to engage in a meaningful way with natural scientists (Sokal, 1996; Yearly, 2005). Conversely, natural scientists by virtue of living in a social world and encountering social systems such as education, welfare or health, have a lay experience that affords them sufficient language that enables them to discuss these matters. Albeit this is from an untrained perspective, but the point is that they are confident to embark on such communication. The same cannot be stated for social scientists engagement with scientific systems.

There is a need for intellectual fluency (Snow, 1993 [1959]) or bilingualism. The capacity to use our own specialist language, but also to engage with and contribute to wider cultural conversations would help to overcome this breakdown of communication and imbalance of power across the disciplines. But more than this, there is a need to recognize the possibility that researchers have the competency to engage in meaningful debate across the disciplines, rather than reinforce the notion that only disciplinary experts are able to comment on their area of expertise. Once this is successfully achieved interdisciplinary researchers can realistically begin to devise paradigms with particular standards by which their research outputs can be measured and judged. Simply mixing disciplines in a school with a traditional disciplinary base was shown to have very limited outcomes.

The process of working across the disciplinary boundaries is fraught and not for the faint hearted. It requires the development of positive working relations, both personal and intellectual. In order to achieve this 'space' in the form of time and resources is more imperative than the physical positioning of disciplines together in a single academic unit. This would allow researchers to develop an understanding of the different disciplines, to foster a shared language and to nurture effective working relations, all from their disciplinary base and 
the intellectual and organizational security that this brings. Until such times the lack of shared paradigms and the uncertainty that accompanies engaging across the disciplines, will ensure that the notion of the 'dubious quality' of interdisciplinary work (Mansilla and Gardner, 2003; see also Nowotny, 2003) prevails. We are then in danger of making faces across the gulf (Snow, 1959), with the two mentalities being further apart than they have ever been in the past fifty years (Sokal, 1996b) and a host of interdisciplinary research opportunities lost forever. 


\section{References}

Aram, J.D. Concepts of interdisciplinarity: Configurations of knowledge and action. Human relations 2004, Vol. 57(4) pp.379-412.

Bachrach, P. and Baratz, M. S. The Two Faces of Power. American Political Science Review 1962, Vol. 56 pp. 947-952.

Becher, T. Academic tribes and territories: Intellectual enquiry and the cultures of disciplines. Buckingham: Society for Research into Higher Education/Open University

Press, 1989.

Bricmont, J. Science studies - what's wrong? Physics World, 1997, last accessed 10/07/06 http://physicsweb.org/articles/world/10/12/2

Colllini, S. Introduction in Snow, C. P. The Two Cultures. Cambridge: Cambridge University Press, 1993.

Denzin, N.K. and Lincoln, Y.S. Entering the field of qualitative research in Denzin, N.K. and Lincoln, Y.S. (eds) Strategies of Qualitative Enquiry. London: Sage, 1998.

Denzin, N.K. and Lincoln, Y.S. Introduction: The discipline and practice of qualitative research in Denzin, N.K. and Lincoln, Y.S (eds) Handbook of Qualitative Research. London: Sage 2000, pp. 1-28.

Filemyr, A. Interdisciplinarity as commitment to social change. Network: Issues and Ideas 1999 Vol. 16(1) pp.8-13.

Flyvbjerg, B. Making Social Science Matter: Why Social Inquiry Fails and How it can Succeed Again. Cambridge: Cambridge University Press, 2001.

Foucault, M. The Archaeology of Knowledge. London: Routledge (2003 [1972]).

Fuller, S. Interdisciplinarity. The loss of the heroic vision in the marketplace of ideas. http://www.interdisciplines.org/interdisciplinarity, 2003 last accessed 10/07/06.

Gibbons, M., Limoges, C., Nowotny, H., Schwartzman, S., Scott, P. and Trow, M. The new production of knowledge: The dynamics of science and research in contemporary societies. London: Sage, 1994.

HM Treasury (2006) Stern Review Report on the Economics of Climate Change. Cambridge University Press.

Klein, J. T. Interdisciplinarity: History, Theory and Practice. Detroit, MI: Wayne State University Press, 1990.

Klein, J.T. Crossing boundaries: Knowledge, disciplines and interdisciplinarities. Charlottesville: The University of Virginia Press, 1996.

Klein, J. T. Interdisciplinarity and complexity: An evolving relationship. Emergence, Complexity and Organization: E:CO Annual, 2004 Vol. 6, pp. 2-10.

Klein, J.T. and Newell, W.H. Advancing interdisciplinary studies. In W.H. Newell (ed.) Interdisciplinarity: Essays from the literature. New York: College Entrance Examination Board 1998 pp. 3-22.

Kockelmans, J.J. Interdisciplinarity and the University: The Dream and the Reality. Issues in Integrative Studies, 1986, Vol. 4 pp. 1-16.

Kuhn, T.S. The Structure of Scientific Revolutions Chicago: University of Chicago Press, 1962.

Lau, L. and Pasquini, M.W. Meeting grounds: perceiving and defining

interdisciplinarity across the arts, social sciences and sciences. Interdisciplinary science reviews 2004, Vol. 29 No. 1, pp.49-64.

Lélé, S. and Norgraad, R.B. Practising Interdisciplinarity. BioScience, 2005 Vol. 55 No.11, pp. 967-975.

Lowe, P. and Phillipson, J. Reflexive Interdisciplinary Research: The Making of a Research Programme on the Rural Economy and Land Use. Journal of Agricultural Economics 2006, Vol. 57, No. 2, pp.165-184.

Lukes, S. Power: a radical view. London: Palgrave Macmillan, 1974.

Mansilla, V.B. and Gardner, H. Assessing Interdisciplinary work at the frontier. An empirical exploration of 'symptoms of quality'. http://www.interdisciplines.org/interdisciplinarity, 2003, last accessed 10/07/06. 
Moxey, A. and White, B. NELUP: Some reflections on undertaking and reporting interdisciplinary Rive Catchment modelling. Journal of Environmental Planning and Management 1998, Vol. 41 (3), pp.397-402.

Nowotny, H. The Increase of Complexity and its Reduction. Emergent Interfaces between the Natural Sciences, Humanities and Social Sciences. Theory, Culture \& Society 2005 Vol. 22(5), pp.15-31.

Nowotny, H., Scott, P., Gibbons M. Re-Thinking Science. Knowledge and the Public in an Age of Uncertainty. Cambridge: Polity Press, 2001.

Nowotny, $\mathrm{H}$. The Potential of Transdisciplinarity.

http:/ / www.interdisciplines.org/interdisciplinarity, 2003, last accessed 10/07/06.

OECD. Interdisciplinarity: Problems of Teaching and Research in Universities. OECD, Paris, 1972.

Shortall, S and McAreavey, R. (2006) Who said interdisciplinary research was fun? Revisiting the differences between the two cultures. Paper presented to the 1st International Conference on Interdisciplinary Social Science. Rhodes, Greece.

Snow, C. P. The Two Cultures. Cambridge: Cambridge University Press, (1993 [1959]).

Sokal, A. Transgressing the Boundaries: Toward a Transformative Hermeneutics of Quantum Gravity. Social Text 1996a, 46/47, pp. 217-252.

Sokal, A. Transgressing the Boundaries: An Afterward. http://www.physics.nyu.edu/faculty/sokal/. 1996b, Last accessed 10/07/06.

Sokal, A. and Bricmont, J. Science and Sociology of Science: Beyond War and Peace. http://www.physics.nyu.edu/faculty/sokal/, 1999, last accessed 10/07/06.

Sperber, D. Why Rethink Interdisciplinarity?

http://www.interdisciplines.org/interdisciplinarity, 2003, last accessed 10/07/06.

Tress, B., Tress, G. and Fry, G. Integrative studies on rural landscapes: policy expectations and research practice. Landscape and Urban Planning 2005, 70 pp. 177- 191.

Yearley, S. Making Sense of Science. Understanding the social study of science. London: Sage, 2005. 